\title{
INVOLVING FAMILY MEMBERS IN THE DELIVERY OF TB CARE IN THE KANDY DISTRICT, SRI LANKA
}

\section{Jayawardena KAS, Medagedara D}

District Chest Clinic, Kandy, Sri Lanka

\begin{abstract}
Objective : To determine the effectiveness of using family members in the delivery of Directly Observed Treatment (DOT) in a local community, Sri Lanka

Method : Thirty nine TB patients detected at the Chest Clinic, Kandy between 1st of September and 31st of December 2007 were given DOT using family members (study group). Treatment outcome of the study group was evaluated in December 2008 and compared with the outcome of 42 patients, who had undergone DOT at peripheral health centres during the same period.
\end{abstract}

Results : Sputum conversion rate at the end of the intensive phase of treatment of the study group was $95 \%$ and the rate of comparison group was $88 \%$. Treatment was successfully completed in $95 \%$ of patients in the study group and $86 \%$ of patients in the comparison group. No defaulters were found in the study group whereas 4 defaulters were in the comparison group. Observed outcome differences between two groups were not statistically significant $(p>0.05)$.

Conclusion : The present study reveals that the treatment outcome is good among patients who receive family DOT. The important prerequisites to ensure successful family DOT include correct selection of patients and DOT providers, giving adequate instruction for treatment adherence, and monitoring of the progress.

Keywords : DOTS, family DOT, Sri Lanka

\section{INTRODUCTION}

The DOTS strategy was implemented in Sri Lanka in the year 1997. By the end of 2005 The DOTS population coverage reached $97.5 \%$ (1). There has been a significant improvement in TB control during the last decade through the implementation of DOTS. The case detection and cure rates among new smear positive cases under DOTS were 84\% (2003) and 83.58\% (for cases registered in 2004) respectively.,

\section{Correspondence to}

Dr. K.A.S. Jayawardena

E.mail: kasjaya60@yahoo.com
Directly Observed Treatment (DOT) is a key element of DOTS strategy which ensures adherence of patients to correct anti TB therapy and thus ensures a high cure rate and prevents development of multi-drug resistant tuberculosis. Health care workers in the state health institutions are the main category of DOT providers in Sri Lanka. The other Programme- recommended categories of treatment providers are public health workers, general practitioners, community leaders and community volunteers. ${ }^{3}$ However, in practice these categories do not play a significant role in providing DOT. The exclusive use of state health centre based DOT, carries certain disadvantages for patients. For example, some patients have to travel long distances 
for treatment on a daily basis loosing money and experiencing physical hardships. Social stigma and loss of income have also been identified as significant problems. In many instances, patients have no other choice than to accept DOT at the nearest state health centre offered by the District Chest Clinic. Since DOT in state health centres is not always convenient for all TB patients, other possibilities of a patient centered delivery of effective treatment have to be explored.

There has been a debate among the doctors working in TB control activities about the suitability of using family members as DOT providers. However, there is no data available about the effectiveness of using family DOT in the local communities, nor the availability of proper guidelines to initiate such practice. Thus family DOT is not currently a recognized practice in the island. The aim of the following study was to evaluate the effectiveness of using family DOT in a local community.

\section{METHOD}

This study was conducted in the Kandy District, located in the Central hills of Sri Lanka. The population of the district is $1,272,500$ (Census 2001) and mainly comprises of a rural Sinhalese community. The literacy rate of this population is nearly $90 \%$ and the life expectancy at birth is 71 years. The district has a good network of health care institutions in the public sector. The Chest Clinic, Kandy administrates and coordinates all TB control activities in the district. There are about 125 DOT centres located in the state health care institutions. This study was based on a comparison of treatment outcome of two treatment groups, namely, the study group (patients who underwent family DOT) and the comparison group (patients who underwent DOT at health centers).

The study group was selected using new tuberculosis patients detected between 1st of September and 31st of December 2007 at the Chest Clinic Kandy. The medical officer, who was assigned to attend on TB patients at the time of arranging DOT, was trained and given the responsibility of the selection of patients and treatment providers for family DOT, using a set of selection criteria (table 01). Both the patient and the selected family member were educated about the disease and emphasized on the value of adhering to correct treatment. Drugs for a prescribed period and the treatment card were handed over to the family member after giving adequate training on how DOT is administered. The family member was further advised to bring the patient to the Chest Clinic for review at weekly intervals during the intensive phase of treatment, and then, at monthly intervals until the treatment was completed. Meanwhile, the Public Health Inspector (PHI) of the Chest Clinic was assigned to monitor the progress of the directly observed treatment at the field level. The comparison group consisted of new TB patients who underwent DOT at peripheral health centres during the same period. These patients were reviewed monthly at the Chest Clinic while monitoring the progress of DOT in the peripheral health centres. The treatment outcome of these two groups was evaluated after a period of one year using three indicators (sputum conversion rate, treatment success rate for all TB cases and default rate). The difference observed in the outcome between the two groups was statistically tested for significance using SAS statistical software.

\begin{tabular}{l}
$\begin{array}{l}\text { Table 1: - Criteria used for selection of } \\
\text { patients and DOT providers for the family } \\
\text { DOT }\end{array}$ \\
$\begin{array}{ll}\text { Patient } & \begin{array}{l}\text { One who wishes to have } \\
\text { treatment daily at home under } \\
\text { the direct supervision of a family } \\
\text { member }\end{array} \\
\text { DOT Provider } & \begin{array}{l}\text { One who lives with the patient in } \\
\text { the same house }\end{array} \\
& \begin{array}{l}\text { Accepted by the patient as the } \\
\text { treatment provider } \\
\text { Literate and skillful }\end{array} \\
& \begin{array}{l}\text { Accountable to the health } \\
\text { system }\end{array}\end{array}$ \\
\hline
\end{tabular}

\section{RESULTS}

Thirty nine patients had been selected for the study group whereas the comparison group consisted of 
42 patients. The mean age of the study group was 46.6 years while in the comparison group it was 39.6 years. There were 21 males and 18 females in the study group and 25 males and 17 females in the comparison group. The numbers of smear positives pulmonary tuberculosis cases were 21 and 25 in the study and comparison groups respectively (table 02 ).

$\begin{aligned} & \text { Table 2: - Distribution of patients by the type } \\
& \text { of TB }\end{aligned}$
\begin{tabular}{|ccc|}
\hline Type of TB & $\begin{array}{c}\text { Study } \\
\text { group }\end{array}$ & $\begin{array}{c}\text { Comparison } \\
\text { group }\end{array}$ \\
$\begin{array}{c}\text { PTB smear } \\
\text { positive }\end{array}$ & 21 & 25 \\
$\begin{array}{c}\text { PTB smear } \\
\text { negative }\end{array}$ & 12 & 12 \\
EPTB & 06 & 05 \\
Total & 39 & 42 \\
\hline
\end{tabular}

\begin{tabular}{|c|c|c|}
\hline Frequency & $\begin{array}{l}\text { Study } \\
\text { group }\end{array}$ & Comparison group \\
\hline $\begin{array}{l}\text { Sputum } \\
\text { converted }\end{array}$ & 20 & 22 \\
\hline Not converted & 01 & 03 \\
\hline Total & 21 & 25 \\
\hline
\end{tabular}

$P=0.6139$

\begin{tabular}{|lll|}
\hline \multicolumn{3}{|c|}{ Table 4: - Treatment success for all TB cases } \\
\hline Frequency & Study group & Comparison group \\
Succeed & 37 & 36 \\
Not succeed & 02 & 06 \\
Total & 39 & 42 \\
\hline
\end{tabular}

$P=0.2666$

\begin{tabular}{|lcc|}
\hline \multicolumn{3}{|c|}{ Table 5: - Treatment compliance } \\
\hline Frequency & Study group & Comparison group \\
Complied & 39 & 38 \\
Defaulted & 00 & 04 \\
Total & 39 & 42 \\
\hline
\end{tabular}

$P=0.1167$
Of the three indicators evaluated, the sputum conversion rate at the end of the intensive phase of treatment of the study group was $95.2 \%$ while the rate in the comparison group was $88 \%$ (table 03 ). The treatment success rate for all TB cases of the study group was $95 \%$ while it was $86 \%$ in the comparison group (table 04). There were no defaulters in the study group whereas 4 (default rate - 9\%) defaulters were detected in the comparison group (table 05). All 3 indicators showed that, the outcome of the study group was better than that of the comparison group. However, categorical data analysis revealed that the differences of observed outcomes between the two groups were not statistically significant $(p>0.05)$.

\section{DISCUSSION}

Adherence to treatment is a critical factor in determining treatment success. ${ }^{4}$ The success of treatment for tuberculosis, assuming an appropriate drug regimen is prescribed, depends largely on patient adherence to the regime. Achieving adherence is not an easy task, either for the patient or the care provider.

The directly observed treatment has generated the most outstanding results in the delivery of TB treatment. When a second individual directly observes a patient swallowing drugs, there is a greater certainty that the patient is actually receiving the prescribed medications. Having a good network of state primary health care centres in Sri Lanka, The National TB Control Programme, has achieved a high success rate in anti TB treatment using health workers as DOT providers. However, defaulting treatment and treatment failures are still substantial in some areas of the island. ${ }^{1}$ We believe that the National Programme is over dependent on state health workers in the delivery of DOT neglecting adequate use of other categories.

Substantial amounts of data are available about the delivery of family DOT in the literature. Okanurak et al reported that in Bangkok, family-based DOT following a short period of DOT given in a clinic, resulted in a higher success rate than DOT given solely in a clinic. ${ }^{5}$ 
A cluster randomized controlled trial in rural Nepal found that family member DOT was as effective as community member DOT. ${ }^{6}$ Thiam et al found that in Senegal, family member DOT resulted in an $88 \%$ cure rate compared with a $77 \%$ cure rate for all other DOT providers. ${ }^{7}$ In Yasothorn Province, Thailand, the overall cure rate was $80.4 \%$ in a programme in which trained and supervised family members provided DOT in two-third of smear positive patients in $1997 .{ }^{8}$ Maclnture et al found that in Victoria, Australia, among patients allocated for family DOT, only $58 \%$ were able to receive DOT, the major reason being living alone and not having a family member to observe treatment. ${ }^{9}$

Sri Lanka has a high literacy rate and family structures are supportive in many settings. The present study reveals that treatment adherence is high among patients who receive family DOT. The important prerequisites to ensure successful family DOT include correct selection of patients and DOT providers, giving adequate instruction for treatment adherence, and supervision of drug intake by home visits. A similar study using a large sample size covering a wide geographical area would help to generalize the findings of the present study.

\section{ACKNOWLEDGEMENTS}

We are grateful to the patients and family members who participated in this study. We sincerely thank Dr. M. Samarathunga, Mr. C.B. Amaranayaka (MRO), and Mr. C. Hewawasam (PHI) of the Chest Clinic, Kandy for their valuable contribution and Ms E. K. Karunarathna of the University of Peradeniya for editing the manuscript.

\section{REFERENCES}

1. National Programme for Tuberculosis Control and Chest Disease. Annual Report 2005. Ministry of Health Sri Lanka, 2005.

2. World Health Organization. DOTS Implementation in Sri Lanka. Report of a Monitoring Mission, 7-15 July 2004. New Delhi: WHO Regional Office for South-East
Asia, 2004.

3. National Programme for Tuberculosis Control and Chest Disease. General Manual for Tuberculosis Control. Ministry of Health Sri Lanka, 2005: 29-30.

4. World Health Organization. Adherence to long-term therapies. Evidence for action. Geneva: World Health Organization, 3003.

5. Okanurak K, Kitayaporn D, Wanarangsikul W, Koompong $\mathrm{C}$. Effectiveness of DOT for tuberculosis treatment outcomes: a prospective cohort study in Bangkok, Thailand. Int J Tuberc Lung Dis 2007; 11: 762-768.

6. Newell JN, Baral SC, Pande SB, Bam DS, Malla P. Family member DOTS and community DOTS for tuberculosis control in Nepal: cluster-randomized controlled trial. Lancet 2006; 367: 903-909.

7. Thiam S, Le Fevre A M, Hane F, et al. Effectiveness of a strategy to improve adherence to tuberculosis treatment in a resource poor setting: a cluster randomized controlled trial. JAMA 2007; 297: 380386.

8. Akkslip S, Rasmithat S, Maher D, Sawert H. Direct observation of tuberculosis treatment by supervised family members in Yasothorn Province, Thailand. Int J Tuberc Lung Dis 1999; 3: 1061-1065.

9. Maclntyre CR, Goebel K,Brown GV, Skull S, Starr M, Fullinfaw RO. A randomised controlled clinical trial of the efficacy of family-based direct observation of antituberculosis treatment in an urban, developed-country setting. Int J Tuberc Lung Dis 2003; 7: 848-854. 